\title{
Einige Schlussfolgerungen
}

Zum Abschluss seien einige Punkte zusammengestellt, die sich aus der Beschäftigung mit der antiken Biographie ergeben haben und die im Rahmen der sich etablierenden Disziplin der historischen Biographik von Bedeutung sein können. 1. In der Antike hat es keine klare Definition der Biographie gegeben. Die personenbezogene Literatur ist darüber hinaus auch keine selbständige literarische Gattung mit eigenen Stilgesetzen und Methoden gewesen. Was man als biographische Literatur ansehen darf und was nicht, ist in der Forschung mehr denn je umstritten.

2. Auf jeden Fall bestand in der Antike stets ein, freilich unterschiedlich motiviertes und auch zeitgebunden divergierendes, Interesse am Individuum und seiner literarischen Präsentation.

3. Evident ist ein Zusammenhang zwischen den politisch-gesellschaftlichen Rahmenbedingungen und der Stellung und Verbreitung der biographischen Literatur: Grundsätzlich haben monarchische Herrschaftsverhältnisse das Entstehen von Biographien begünstigt.

4. Schon relativ früh hat sich die autobiographische Darstellungsform durchgesetzt, und von Anfang an diente sie, wie die altorientalischen Vorläufer (oder Vorbilder) der Rechtfertigung politischen Handelns.

5. Biographie realisierte sich in der Antike entweder als eine Faktenbiographie oder als eine Charakterstudie. Bei letzterer war der Übergang zum Enkomion oder auch zum Fürstenspiegel fließend.

6. Es ist ein lohnendes Unternehmen, die antiken Biographien als historische Quellen zu betrachten (unabhängig von ihrem jeweiligen literarischen und ästhetischen Wert). In dieser Hinsicht zeigt sich zweierlei: Die antike Biographie ist zum einen eine reiche Quelle für Fakten und Verhältnisse, die ansonsten in den Quellen keine Erwähnung finden. Und zweitens ist auch bereits das Faktum der biographischen Darstellung ein Erkenntniswert, denn es dokumentiert die jeweilige Präferenz individuellen Agierens gegenüber kollektivem Handeln. 